\title{
Availability and category-frequency estimation
}

\author{
DARRYL BRUCE \\ Mount Allison University, Sackville, New Brunswick, Canada \\ WILLIAM E. HOCKLEY \\ Wilfrid Laurier University, Waterloo, Ontario, Canada \\ and \\ FERGUS I. M. CRAIK \\ University of Toronto, Toronto, Ontario, Canada
}

\begin{abstract}
Individuals judged how often examples of taxonomic categories had occurred in a study list. An availability hypothesis was tested-that frequency estimates are based on the retrieval of instances. Cued (by category names) recall of the examples served as an index of availability. The hypothesis was confirmed-there were strong positive correlations between frequency judgments and recall (with the influence of actual frequency removed)-given one or more of the following conditions: List instances were not categorized aloud as they were presented; frequency estimation was preceded by cued recall; frequency estimation was delayed by a week. Limitations on availability occurred under other conditions-notably, when individuals, during list presentation, named the categories to which items belonged and received feedback about their categorizations. Under these circumstances, correlations of frequency estimation and recall were often not significantly different from zero, and frequency judgments and recall sometimes reacted differently to changes in independent variables (e.g., frequency judgments of young and elderly subjects did not differ reliably, even though cued recall of young persons markedly exceeded that of elderly subjects).
\end{abstract}

Tversky and Kahneman (1973) proposed that in judgments of the frequency with which members of a class have occurred, an availability heuristic may be usedthat is, frequency will be evaluated by the ease with which relevant instances come to mind. The experiments to be reported here were aimed at assessing the applicability of this hypothesis to the making of category-frequency judgments of episodic events. The task adopted was introduced by Alba, Chromiak, Hasher, and Attig (1980) and has since been used by others (e.g., Williams \& Durso, 1986). In the present version, varying numbers of words were selected from common conceptual categories (e.g., animals and musical instruments) and shown to individuals in a random order. At the end of the list, names of the categories were presented, and the subjects were asked to estimate how many times words belonging to them had occurred in the study list.

This research was supported by a National Research Service Award to D. Bruce from the United States National Institute on Aging and by Natural Sciences and Engineering Research Council of Canada grants to D. Bruce, F. I. M. Craik, and B. B. Murdock, Jr. We thank the following persons for contributions to the work reported in this article Paul Boase, Susan Bour, Heather Faulkner, David Hearn, David Hultsch, Maureen Irvine, Ruth Loewen, Lorna Morris, Wendy Perkins, Donald Tutty, Alison Warner, and Bruce Whittlesea. We also thank the editor and consulting editors for constructive reviews of earlier versions of the manuscript. Address correspondence to Darryl Bruce, who is now at the Department of Psychology, Saint Mary's University, Halifax, Nova Scotia B3H 3C3, Canada.
As applied to this task, an availability hypothesis will be taken to mean the following: The occurrence of a category instance on the study list establishes a separate memory trace (see, e.g., Hintzman, 1988). On the frequencyjudgment test, each category name cues the retrieval of instances. Subjects base their frequency judgments in some manner on the exemplars retrieved. A number of considerations may influence the frequency judgments that are given. For example, individuals may conclude that they do not remember all instances of a category and so add an allowance for items forgotten; or they may infer higher frequency because the instances came to mind easily, which is Tversky and Kahneman's (1973) original idea of availability. Greene (1989) has termed this account of availability an exemplar-retrieval hypothesis.

In our investigations, recall cued by category names was used as a measure of availability (cf. Greene, 1989; Tversky \& Kahneman, 1973; Williams \& Durso, 1986). Since frequency estimation (on an availability view) and cued recall involve the recollection of instances, a common retrieval process may be said to operate in both kinds of test. To the extent that this common process is a source of stable variability across tests, two kinds of evidence for availability should be found: (1) The two dependent measures should be positively correlated; (2) they should respond in the same direction to changes in independent variables.

The results to date have been mixed. On the one hand, Greene (1989), Lewandowsky and Smith (1983), Tversky 
and Kahneman (1973), and Williams and Durso (1986) have found that recall and frequency judgments are positively correlated or similarly sensitive to changes in independent variables or both. On the other hand, Barsalou and Ross (1986) have observed that while recall increases as a function of the frequency of instances of property categories (e.g., things that are red), frequency estimates do not. Freund and Hasher (1989) have found that frequency estimation but not recall depends on whether or not subjects received advance information about the categorical nature of the study list.

In the present research, a number of different experimental conditions were investigated, with the purpose of evaluating the degree and consistency of the correlation between category-frequency judgments and cued recall and of determining whether the two measures would respond in similar fashion to changes in selected independent variables. Taken together, the studies provide a strong test of the applicability and generality of the availability or exemplar-retrieval hypothesis.

\section{EXPERIMENT 1}

Our intent in Experiment 1 was to establish conditions under which an availability heuristic might operate. A long list of category instances was presented, followed by two tests: frequency estimation and cued recall. Half the time, frequency estimation came first, and half the time, cued recall came first. The other key independent variable was whether or not subjects explicitly categorically encoded study items during list presentation. In one condition, they did; in another, they did not. The purpose of this manipulation was to determine the applicability of an availability heuristic as a function of variation in the strength of categorical encoding of list items.

\section{Method}

Materials and Design. Subjects saw a list of 156 words selected from a pool of 11 typical examples of 30 semantic categories. Materials were drawn primarily from the Battig and Montague (1969) norms, but some came from the norms of McEvoy and Nelson (1982).

There were three independent variables. One was actual frequency-each category was represented in the list by $0,2,5,8$, or 11 instances. Each frequency level occurred six times.

A second independent variable was the order of the frequencyjudgment and cued recall tests. Half the time cued recall came before frequency estimation (recall before), and half the time it came after (recall after). When it came after, frequency estimation was preceded by distractor activity lasting $12.5 \mathrm{~min}$, the time allowed for recall. The distractor activity consisted of a vocabulary test and then a task of writing down where each of a number of commonplace events might have happened. The vocabulary test, which took a maximum of $8 \mathrm{~min}$, was made up of 36 multiple-choice items from Part 1 of the V-2 and V-4 tests described in Ekstrom, French, Harman, and Dermen (1976).

It should be appreciated that the recall test was administered earlier in the recall-before than it was in the recall-after condition, but the delay in administering the frequency-judgment test was kept constant. Because preliminary research (Bruce \& Read, 1988) had indicated that an initial recall test was likely to depress later frequency estimates, it was deemed important that such an effect not be con- founded by differences between the two conditions in how long after the end of the list the frequency-judgment test occurred.

The final independent variable was encoding activity. In the nocategorization condition, subjects repeated each word aloud as it was presented. In the categorization condition, individuals were given $3 \mathrm{sec}$ to name the category to which each list word belonged and were then shown the correct category label below the word. The experimenter noted items that were incorrectly categorized.

The study list and frequency test were presented in 40-column mode on the monitor of an Apple IIGS computer. The sequence of 156 study-list items was random, except that consecutive occurrences of members of the same category were prohibited. The sequence of 30 category names on the frequency test was also random. Within each experimental condition, each subject received a unique list and test. Across conditions, however, the lists and tests were the same. In constructing a study list, six categories were randomly assigned to each of the actual frequency levels from 0 to 11. For each nonzero category, the choice of list items was a random selection of the 11 instances available in each category of the word pool.

Procedure. At the outset of an experimental session, the subjects were given training on the categories. A typed list of the 30 category names was studied (each was a one- or two-word label, such as FURNITURE and BODY PART), and then a written stem-completion test of the names was administered (e.g., FU _ _ _ _ and $\mathrm{BO}$ _- PA _ $)$. This procedure was continued until a score of 21 or more out of 30 was reached.

Instructions about the study list were then shown on the monitor. The subjects were told that a memory test would be given at the end of the list and that they would receive more information about the test at that time. The words were shown at a 4.5-sec rate ( $4 \mathrm{sec}$ on-time, $.5 \mathrm{sec}$ between items). In the categorization treatment, each word appeared by itself for $3 \mathrm{sec}$, and then the category label appeared below it for the final second of the 4-sec exposure interval.

Following list presentation, the recall-after groups completed the distractor, frequency-estimation, and recall tasks in that order; the recall-before groups completed the recall test and then the frequencyjudgment task. The instructions for the frequency-judgment test were presented on the computer monitor. The list of 30 category names then followed. As each was presented, an individual stated how many examples from the category had occurred in the list, and the experimenter recorded the response. The subjects were given $12 \mathrm{sec}$ in which to make their estimates and to press the space key to bring up the next category name. If they had not responded by the end of that time, they were prompted to do so by a visually displayed message and a coincident beep.

The cued recall test was a four-page booklet with approximately one quarter of the 30 category labels suitably spaced down the left side of each page. Recalled items were written alongside the appropriate category names. Three different booklets differing in the order of the category cues were used.

Subjects. Sixty subjects, 43 females and 17 males, were tested. An equal number were randomly assigned to the four independent groups (representing the factorial combination of the test order and encoding variables), except that the ratio of males to females was comparable across groups. Participants, who were drawn from classes in introductory psychology at Mount Allison University (hereafter referred to as the Mount Allison subject pool), received course credit for their participation.

\section{Results}

For each subject in this experiment and in all subsequent experiments, four dependent measures were calculated: (1) on each frequency test, mean frequency estimates at each level of actual frequency; (2) on each 
frequency test, the slope of the regression function relating estimated to actual frequency-a measure of frequency discrimination (see Naveh-Benjamin \& Jonides, 1986); (3) on each frequency test, the standard deviation of frequency judgments obtained by averaging across the standard deviation of frequency judgments at each level of actual frequency - a measure of reliability of frequency estimates (see Naveh-Benjamin \& Jonides); and (4) on the cued recall test, mean cued recall at each level of actual frequency. Because we were interested in frequency discrimination and not recognition, the results, unless otherwise indicated, exclude performance at the frequency level of 0 (cf. Birnbaum, Taylor, Johnson, \& Raye, 1987; Greene, 1984, 1986, 1988; Jonides \& Naveh-Benjamin, 1987; Naveh-Benjamin \& Jonides, 1986). The alpha level for all statistical tests was $p<.05$. To reduce statistical clutter, we report inferential statistics only if $p<.10$.

Frequency judgments. The first five data columns of Table 1 set forth mean frequency judgments as a function of actual frequency and overall means for each condition of the experiment. Estimates were significantly higher when list items were categorized during study $[F(1,56)=20.24]$ and when recall followed frequency estimation $\left[F(1,56)=23.62 ; M S_{\mathrm{e}}=4.34\right.$ in both cases $]$. The main effect of actual frequency was also statistically significant $[F(3,168)=223.75]$, as was the interaction of actual frequency and categorization $[F(3,168)=4.96$; $M S_{\mathrm{e}}=.85$ in both cases]. The interaction of actual frequency and position of the recall test was not reliable $\left[F(3,168)=2.29, M S_{\mathrm{e}}=.85\right]$.

Judgments at the frequency level of 0 were higher in the no-categorization groups than in the categorization groupsmeans were .48 versus .06 when recall preceded frequency estimation and .97 versus .49 when recall followed frequency judgments. Both categorization and position of the recall test had statistically significant main effects $\left[F(1,56)=4.54\right.$ and 4.77 , respectively, $\left.M S_{\mathrm{e}}=.67\right]$.

Slopes and standard deviations. Table 1 also sets forth slopes and standard deviations of frequency estimates in each condition of the experiment. Slopes were steeper under categorization $[F(1,56)=7.52]$, and marginally so $(p<.06)$ when recall followed frequency estimates $\left[F(1,56)=3.84 ; M S_{\mathrm{e}}=.03\right.$ in both cases $]$. The variability of frequency estimates was much less when cued recall occurred prior to frequency judgments $[F(1,56)=12.32$, $\left.M S_{\mathrm{e}}=.44\right]$. No other effects on either slopes or standard deviations were statistically significant.

Table 1

Mean Judged Frequency as a Function of Actual Frequency and Overall Means $(M)$, Slopes, and Standard Deviations (SD) of Judgments in Experiment 1

\begin{tabular}{clccccccc}
\hline & & \multicolumn{9}{c}{ Actual Frequency } & & & \\
\cline { 3 - 8 } Categorize & Recall & 2 & 5 & 8 & 11 & $M$ & Slope & $S D$ \\
\hline \multirow{2}{*}{ No } & After & 2.42 & 3.74 & $\mathbf{4 . 9 4}$ & 6.36 & 4.37 & .43 & 1.99 \\
& Before & 1.48 & 2.77 & 3.78 & 4.78 & 3.20 & .36 & 1.43 \\
\multirow{2}{*}{ Yes } & After & 2.96 & 5.07 & 6.72 & 8.12 & 5.72 & .57 & 1.82 \\
& Before & 1.91 & 3.76 & 5.36 & 6.06 & 4.27 & .47 & 1.17 \\
\hline
\end{tabular}

Table 2

Mean Cued Recall as a Function of Actual Frequency and Overall Means $(M)$ in Experiment 1

\begin{tabular}{clccccc}
\hline & & \multicolumn{5}{c}{ Actual Frequency } \\
\cline { 2 - 6 } Categorize & Recall & \multicolumn{1}{c}{. } & 5 & 8 & 11 & $M$ \\
\hline \multirow{2}{*}{ No } & After & .94 & 1.82 & 2.78 & 3.62 & 2.29 \\
& Before & .86 & 1.70 & 2.70 & 3.73 & 2.25 \\
Yes & After & 1.19 & 2.34 & 3.09 & 4.02 & 2.66 \\
& Before & 1.24 & 2.57 & 3.41 & 4.07 & 2.82 \\
\hline
\end{tabular}

Cued recall. Recall protocols were scored in two ways. Under strict scoring, only words recalled that had been on the list were counted as correct; under lenient scoring, words recalled that belonged to a list category were counted as correct, regardless of whether they had actually been presented. The effects were not different for the two types of scoring, and this was true of the data from all subsequent experiments. Because a lenient criterion is more in keeping with the idea of availability-words thought to have been presented even though they were not could influence frequency estimates (cf. Williams \& Durso, 1986)-only descriptions of analyses of recall based on lenient scoring are given throughout this report.

Cued recall scores and group means are presented in Table 2. There were two reliable effects: Word recall increased as a result of categorization during study $[F(1,56)$ $\left.=8.27, M S_{\mathrm{e}}=1.62\right]$ and as a function of actual frequency $\left[F(3,168)=294.32, M S_{\mathrm{e}}=.29\right]$.

Errors in classifying words. Error percentages in classifying words during list presentation in the categorization condition were as follows: $9.5 \%$ for the recall-after group and $8.6 \%$ for the recall-before group. We checked whether the values of any of our dependent measures would change markedly if categories for which more than one incorrect classification had occurred were omitted from consideration (11.1\% of the data on average for the two categorization groups). The differences were negligible for all dependent variables. For example, across the actual frequency levels of $2,5,8$, and 11 , mean frequency estimates based on the reduced-error data in the categorization recall-after condition were as follows (means for the data inclusive of errors are given in parentheses): 2.90 (2.96), 5.17 (5.07), $6.96(6.72)$, and $8.26(8.12)$. The data of subsequent experiments to be reported also depended little on the accuracy of initial categorical encoding. Thus, no further mention of categorization errors during list study is made in this article.

Correlations. Table 3 describes zero-order or simple correlations between estimates on the frequency-judgment test $(T)$ and actual frequency $(F)$ and between frequency estimation and cued recall (R). In Table 3, these correlations are referred to as TF and TR, respectively. The firstorder correlation between each pair of variables is also presented: $T F / R$ and $T R / F$ (the final letter refers to the variable statistically controlled-recall and frequency, respectively). Each correlation is based on the 360 cases (15 subjects $\times 24$ list categories) in a group.

All zero-order correlations were highly reliable. As for the partial correlations, the first-order correlation between 
Table 3

Correlations Involving Frequency Judgments in Experiment 1

\begin{tabular}{clllll}
\hline & & \multicolumn{4}{c}{ Correlation } \\
\cline { 3 - 6 } Categorize & Recall & TF & TF/R & TR & TR/F \\
\hline \multirow{2}{*}{ No } & After & $.48^{*}$ & $.29^{*}$ & $.48^{*}$ & $.30^{*}$ \\
& Before & $.58^{*}$ & $.15^{*}$ & $.79^{*}$ & $.66^{*}$ \\
\multirow{2}{*}{ Yes } & After & $.63^{*}$ & $.48^{*}$ & $.47^{*}$ & .05 \\
& Before & $.68^{*}$ & $.50^{*}$ & $.57^{*}$ & $.26^{*}$ \\
\hline
\end{tabular}

Note $-\mathrm{T}=$ frequency-judgment test, $\mathrm{F}=$ actual frequency, $\mathrm{R}=$ cued recall. ${ }^{*} p<.01$.

judged frequency and cued recall in the no-categorization condition was of intermediate size when recall followed frequency estimation and quite substantial when recall preceded frequency estimation. For the categorization condition, the same partial correlations were essentially zero for the recall-after group and of intermediate magnitude for the recall-before group. Thus, when list instances were not categorized during list study, frequency estimates were more strongly associated with cued recall, particularly when recall preceded frequency judgments. But when list instances were categorized initially, frequency judgments were more strongly associated with actual frequency, especially when recall followed frequency estimation.

\section{Discussion}

Some of the findings support the predictions of the availability hypothesis described at the outset of this article. In the no-categorization treatment, the correlations between frequency judgments and cued recall, absent the influence of actual frequency, were moderate to strong; in the categorization condition, the correlation was moderate when recall came before frequency judgments. In addition, frequency judgments and cued recall showed parallel movement due to variation in encoding activity: Frequency estimates and cued recall both improved when study list items were categorized.

Nevertheless, the data were not uniformly in line with expectations of the availability hypothesis. The partial correlation between frequency judgments and recall for the recall-after categorization group was not reliably different from zero. And when frequency estimates were made before a recall test, they were higher, more variable, and slightly more discriminating than when they were made after such a test; by contrast, recall scores were unaffected by the order of the tests.

The results may be taken to suggest that subjects will resort to an availability heuristic when list items have not been strongly categorically encoded, when recall precedes frequency estimates, or both. Weak initial categorical encoding evidently forces subjects into a deliberate search for exemplars upon presentation of the category label on a frequency-judgment test, with estimates being based on the results of that search. A recall test prior to frequency estimation necessarily induces instance retrieval, and subsequent estimates can be based on memory of the results of such retrieval. In combination, the two conditions will virtually guarantee use of an availability strategy.

In contrast, when individuals attempt to name the category membership of each study list item as it is presented and when they receive feedback about such membership, simple recollection of the number of times that a category name has been experienced during the presentation of the list may suffice. A theoretical interpretation of such an approach is still called for, of course. Indeed, an availability interpretation may have a role to play in such an approach. We explore this possibility in the studies that follow by using the procedure of overt categorization and feedback during presentation of the study list.

\section{EXPERIMENT 2}

In Experiment 2, the categorization recall-after and recall-before conditions of Experiment 1 were repeated. In addition, two groups were tested approximately 1 week after list presentation. One recalled the list items after making frequency judgments; the other, before making such judgments. We suspected that delaying frequency estimation for a week might be more likely to make subjects base their judgments on the recollection of category instances presented a week earlier. In other words, we anticipated that individuals would resort to an availability strategy even though list members had been overtly categorized initially. Thus, we expected to find higher correlations between frequency judgments and recall when testing occurred after 1 week as compared with shortly after list presentation.

\section{Method}

The materials were identical to those of Experiment 1, and the procedure was the same as it was in the categorization condition of the first study. There were three independent variables. One was the order in which the frequency and cued recall tests occurred. Half the time cued recall came after frequency estimation (recall after); half the time it came before (recall before). When it came after, distractor activity identical to that of Experiment 1 preceded frequency estimation and lasted $12.5 \mathrm{~min}$, the time allowed for recall. The second independent variable was the time of testingshortly after the end of the study list or 1 week later. The former treatment is termed the 12.5-min delay; the latter, the 1-week delay. These delays refer to the interval between the end of the list and administration of the frequency test. Thus the recall test was again administered earlier in the recall-before than in the recallafter condition, but the delay in administering the frequencyjudgment test was kept constant. The third independent factor was actual frequency, which varied as in Experiment 1.

Sixty students at Mount Allison University (from the subject pool or paid volunteers) were tested, 29 females and 31 males. In each 15-person experimental group, the number of females was approximately the same as the number of males.

\section{Results}

Frequency judgments. Table 4 presents mean judgments at the frequency levels from 2 to 11 and the overall mean for each group. Cued recall before frequency estimation depressed judgments at both retention inter- 
Table 4

Mean Judged Frequency as a Function of Actual Frequency and Overall Means $(M)$, Slopes, and Standard Deviations $(S D)$ of Judgments in Experiment 2

\begin{tabular}{clccccccc}
\hline & & \multicolumn{9}{c}{ Actual Frequency } & & & \\
\cline { 2 - 7 } Delay & Recall & 2 & 5 & 8 & 11 & $M$ & Slope & $S D$ \\
\hline $12.5 \mathrm{~min}$ & After & 2.68 & 4.82 & 7.01 & 8.72 & 5.81 & .68 & 1.75 \\
& Before & 2.20 & 4.06 & 5.76 & 6.83 & 4.71 & .52 & 1.18 \\
1 week & After & 3.00 & 4.51 & 5.88 & 6.67 & 5.01 & .41 & 2.07 \\
& Before & 2.36 & 3.40 & 3.94 & 4.57 & 3.57 & .24 & 1.42 \\
\hline
\end{tabular}

vals $\left[F(1,56)=12.31, M S_{\mathrm{e}}=7.89\right]$. Frequency estimates also dropped significantly after a week's delay in testing $\left[F(1,56)=7.15, M S_{\mathrm{e}}=7.89\right]$. The only other statistically significant effects were due to actual frequency $[F(3,168)=234.89]$ and its interaction with test order $[F(3,168)=7.52]$ and test delay $[F(3,168)=20.39$; $M S_{\mathrm{e}}=.83$ in all cases]. Estimates at the frequency level of 0 were substantially higher in the 1 -week as compared with the 12.5 -min condition, 1.01 versus $.19[F(1,56)=$ $\left.15.85, M S_{\mathrm{e}}=.62\right]$.

Slopes and standard deviations. The mean slopes for the four experimental conditions are also reported in $\mathrm{Ta}$ ble 4 . By this measure, frequency discrimination was significantly impaired when preceded by cued recall $[F(1,56)$ $\left.=12.48, M S_{\mathrm{e}}=.03\right]$ and after a test delay of 1 week $\left[F(1,56)=34.32, M S_{\mathrm{e}}=.03\right]$. The final column of Table 4 contains mean standard deviations of frequency judgments. Variability in estimates declined when a recall test preceded the frequency test $\left[F(1,56)=13.41, M S_{\mathrm{e}}=\right.$ $.42]$, but it was largely unaffected by retention interval $\left[F(1,56)=2.81, M S_{\mathrm{e}}=.42\right]$.

Cued recall. Means for leniently scored cued recall are set forth in Table 5. Recall increased significantly with actual frequency $\left[F(3,168)=159.26, M S_{\mathrm{e}}=.30\right]$ and decreased when testing was delayed by a week $[F(1,56)=$ 42.73, $M S_{\mathrm{e}}=1.49$ ]. These two variables also interacted: As frequency level increased, so did the decline attributable to the retention interval $\left[F(3,168)=18.10, M S_{e}=.30\right]$.

The point at which cued recall occurred relative to the frequency test interacted with delay. Simple effects tests disclosed that at the 12.5-min delay, performance in the recall-before group was significantly superior to that of the recall-after group $\left[F(1,56)=4.82, M S_{\mathrm{e}}=1.49\right]$ (it should be remembered that the recall-before retention interval was shorter). At the 1-week delay, the difference was in the other direction but not reliably so $[F(1,56)=$ $3.09, M S_{\mathrm{e}}=1.49$ ].

Correlations. Simple and first-order partial correlations were calculated as in Experiment 1 and are reported in Table 6 . The notation used to designate the correlations is the same as that in Table 3. All zero-order coefficients between judged and actual frequency and judged frequency and recall were statistically significant and were somewhat larger in the $12.5-\mathrm{min}$ as compared with the 1-week groups.

As in the comparable categorization groups of Experiment 1 , first-order correlations for frequency estimates delayed by 12.5 min were more strongly related to actual frequency than to recall. In contrast, when frequency estimates were delayed by a week, the associations between judged and actual frequency were weaker and those between judged frequency and cued recall were somewhat larger, especially in the 1-week recall-after group.

\section{Discussion}

In Experiment 2, the partial correlations between frequency estimates and cued recall were relatively stronger when testing took place 1 week, rather than immediately, after list presentation. This indicates a greater role for availability if frequency judgments are delayed until considerably after the target events have occurred. One caveat is that although the correlations generally did not differ according to whether recall was scored leniently or strictly, there was one exception: The first-order correlation between frequency estimation and recall in the 1-week recallafter group was .32 under lenient scoring but only .21 under strict scoring. The higher association may be due in part to the influence of frequency judgments (which came first) on recall (which came second), not the reverse.

The 1-week delay in frequency and recall tests had a similar negative influence on frequency judgments and cued recall. The parallel effects are consistent with an availability interpretation of frequency estimation. But the position of the recall test relative to frequency estimation produced another dissociation as in Experiment 1. Frequency judgments of the recall-after as compared with the recall-before groups at both delays were higher, more discriminating, and more variable. Yet recall scores were not significantly different (1-week condition) or were actually significantly less (12.5-min condition) in the recallafter group. If availability were driving frequency estimates, this pattern of results should not have occurred.

A possible concern about the dissociation in the 12.5min delay condition is that recall in the recall-after group

Table 5

Mean Cued Recall as a Function of Actual Frequency and Overall Means $(M)$ in Experiment 2

\begin{tabular}{clrcccc}
\hline & & \multicolumn{5}{c}{ Actual Frequency } \\
\cline { 3 - 6 } Delay & Recall & 2 & 5 & 8 & 11 & $M$ \\
\hline $12.5 \mathrm{~min}$ & After & 1.31 & 2.16 & 3.00 & 3.86 & 2.58 \\
& Before & 1.46 & 2.67 & 3.71 & 4.44 & 3.07 \\
1 week & After & 1.20 & 1.77 & 2.13 & 2.87 & 1.99 \\
& Before & .96 & 1.51 & 1.77 & 2.17 & 1.60 \\
\hline
\end{tabular}

Table 6

Correlations Involving Frequency Judgments in Experiment 2

\begin{tabular}{clllll}
\hline & & \multicolumn{4}{c}{ Correlation } \\
\cline { 3 - 6 } Delay & Recall & TF & TF/R & TR & TR/F \\
\hline $12.5 \mathrm{~min}$ & After & $.67^{*}$ & $.53^{*}$ & $.50^{*}$ & $.13 \dagger$ \\
& Before & $.72^{*}$ & $.51^{*}$ & $.64^{*}$ & $.31^{*}$ \\
1 week & After & $.44^{*}$ & $.33^{*}$ & $.43^{*}$ & $.32^{*}$ \\
& Before & $.36^{*}$ & $.23^{*}$ & $.46^{*}$ & $.38^{*}$
\end{tabular}

Note- $T=$ frequency-judgment test, $F=$ actual frequency, $R=$ cued recall. ${ }^{*} p<.01 .+p<.05$. 
was lower than in the recall-before group because the test came later and after a good deal of interpolated activity. Yet although this may be true, it does not diminish the significance of the dissociation. On an availability view, lower recall in the 12.5-min recall-after as compared with the recall-before condition implies correspondingly lower frequency judgments. But the result was just the opposite.

In sum, Experiment 2 adds the following information about the operation of availability when list members have been overtly classified at the time of input: Individuals appear to rely more on the retrieval of instances in making frequency judgments if tests are administered after a week's delay rather than immediately. As for the parallel effects of independent variables on recall and frequency estimation, this was true in the case of delayed testing but not for position of the recall test relative to frequency estimation.

\section{EXPERIMENT 3}

In Experiment 3, there were two purposes. First, we examined again the effect of a cued recall test on frequency estimation. Of particular interest was a preliminary result obtained by Bruce and Read (1988), who used the categorical materials and the overt categorization and feedback procedure of Experiments 1 and 2. In the treatment conditions of interest, subjects received two frequencyjudgment tests separated by a 12.5 -min cued recall test of the list items. On the average, judged category frequency on the first test was 5.67 instances, and on the second test, it was 4.42 instances. Experiments 1 and 2 implicate the recall activity itself as a prime cause of the lower frequency estimates on the second test. To confirm this, however, a more definitive study was necessary. Experiment 3 was a step toward this requirement.

Our second purpose was to examine frequency judgments and cued recall as a function of the age of the subject. Elderly subjects are known to be poorer than young subjects at cued recall of category exemplars (Hultsch, 1975). Would their category-frequency judgments be correspondingly lower, as is implied by the availability hypotheses?

\footnotetext{
Method

Materials and Design. The materials, except for slight editorial changes, were the same as they were in the first two experiments.
}

Following the study list, individuals completed two frequencyestimation tasks separated by $12.5 \mathrm{~min}$. The order of the category names on the two tests was different.

There were four independent groups representing the factorial combination of age (young vs. elderly subjects) and the activity during the 12.5-min interval between the first and second frequency tests (a cued recall test or distractor tasks, as in Experiments 1 and 2). Individuals given the recall test belonged to what will hereafter be termed the recall condition; those given the distractor tasks belonged to what will sometimes be called the distractor and sometimes the no-recall condition.

Procedure. Categorization and feedback during list presentation was again used. This time, materials were presented with an IBMcompatible personal computer. All elderly subjects, except for 1 , saw the materials displayed in 40 -column mode. Young persons and the remaining elderly subject were tested with a computer that had only 80-column capability. Thus, smaller print was used for young subjects as opposed to most of the elderly subjects. This does not appear to be a problem, because the young group in this experiment gave results similar to those of the similarly treated young group in the preliminary study by Bruce and Read (1988), and in that study, materials were presented in the larger print mode.

Two minor changes were made in the frequency test: There was no prompt after $12 \mathrm{sec}$ to make a response; and instead of pressing the space bar after giving a frequency estimate, subjects pressed a key in a slot in a panel covering the keyboard.

Subjects. Sixty subjects (half young and half elderly) were tested, 39 females and 21 males. There were more females than males in each experimental condition, except in the elderly recall group, which had a few more males. The mean age of young persons was 20.6 years (range 17-35); for elderly persons, it was 70.1 (range 61-80).

Of the elderly subjects, 29 were recruited from a list of volunteers maintained by Erindale College, and 1 was from the Mount Allison University area. Young persons were drawn from the Mount Allison subject pool. Because of the difficulty in recruiting young persons during the early phase of testing, data collection from elderly subjects was almost entirely completed before any young subjects were tested.

\section{Results}

Frequency judgments. The first five data columns of Table 7 show mean frequency judgments at each level of actual frequency and the overall mean for each combination of age, presence or absence of cued recall, and test number. The main effect of actual frequency was statistically significant $\left[F(3,168)=249.78, M S_{e}=2.79\right]$. Frequency also interacted with the presence or absence of cued recall $\left[F(3,168)=5.72, M S_{e}=2.79\right]$, with test number $\left[F(3,168)=17.89, M S_{\mathrm{e}}=.71\right]$, and with both cued recall and test number $\left[F(3,168)=2.85, M S_{\mathrm{e}}=\right.$ .71]. The essence of these effects is that although fre-

Table 7

Mean Judged Frequency as a Function of Actual Frequency and Overall Means $(M)$, Slopes, and Standard Deviations (SD) of Judgments in Experiment 3

\begin{tabular}{llcccccccc}
\hline & & & \multicolumn{7}{c}{ Actual Frequency } \\
\cline { 3 - 10 } Age & Condition & Test & 2 & 5 & 8 & 11 & $M$ & Slope & $S D$ \\
\hline Young & No recall & 1 & 3.07 & 5.82 & 8.70 & 9.97 & 6.89 & .79 & 2.12 \\
& & 2 & 2.70 & 5.72 & 7.87 & 9.18 & 6.37 & .72 & 1.99 \\
& Recall & 1 & 2.66 & 5.14 & 6.63 & 8.44 & 5.72 & .63 & 1.69 \\
& & 2 & 2.10 & 3.93 & 4.71 & 5.91 & 4.16 & .41 & 1.05 \\
Elderly & No recall & 1 & 3.31 & 5.56 & 7.93 & 9.82 & 6.66 & .73 & 2.11 \\
& & 2 & 3.17 & 5.20 & 6.80 & 8.67 & 5.95 & .60 & 1.82 \\
& \multirow{6}{*}{ Recall } & 1 & 2.81 & 5.44 & 7.52 & 8.64 & 6.11 & .65 & 1.89 \\
& & 2 & 1.58 & 3.64 & 4.50 & 5.48 & 3.80 & .42 & 1.27 \\
\hline
\end{tabular}


quency estimates increased with actual frequency, they did so to a much smaller degree on Frequency Test 2 when it was preceded by cued recall. Except as noted below, age by itself or in interaction with any other factor did not significantly influence frequency judgments.

The recall and test variables interacted reliably. Simple effects analyses showed that the difference between the recall and distractor conditions was reliable on the second frequency test $\left[F(1,56)=36.66, M S_{\mathrm{e}}=7.78\right]$, but not on the first one $\left[F(1,56)=1.97, M S_{\mathrm{e}}=22.57\right]$.

At Frequency Level 0 , elderly persons gave substantially higher mean frequency estimates, .86 , than did young subjects, . $13\left[F(1,56)=10.35, M S_{\mathrm{e}}=1.56\right]$. No other effects at this level were statistically significant, including those attributable to the presence of the intervening recall test $\left[F(1,56)=3.26, M S_{\mathrm{e}}=1.56\right]$.

Slopes. The slopes described in Table 7 mirror the picture given by the frequency estimates. There was a significant interaction of test and the presence or absence of recall. Simple effects analyses disclosed that individuals receiving a cued recall test showed reliably lower slopes on Test $2\left[F(1,56)=21.82, M S_{\mathrm{e}}=.04\right]$, but not on Test $1\left[F(1,56)=2.30, M S_{\mathrm{e}}=.09\right]$. Again, there were no statistically significant effects due to the age factor.

Standard deviations. The final column of Table 7 sets forth standard deviations of frequency judgments averaged across the four frequency levels from 2 to 11 . As with slopes, there was an interaction of the presence or absence of recall and test number. Simple effects analyses showed that frequency estimates were substantially less variable in the recall condition than in the no-recall condition on Test $2\left[F(1,56)=15.44, M S_{\mathrm{e}}=.54\right]$, but not on Test $1\left[F(1,56)=1.21, M S_{\mathrm{e}}=1.31\right]$. Again, there were no significant age effects.

Cued recall. Across the four frequency levels from 2 to 11 , mean items recalled by young subjects according to a lenient scoring criterion were $1.38,2.75,3.57$, and 4.49; the corresponding figures for elderly subjects were $.61,1.54,2.08$, and 2.75 . The main effects of age and frequency were both reliable $\left[F(1,28)=43.11, M S_{\mathrm{e}}=\right.$ 1.18 , and $F(3,84)=144.51, M S_{\mathrm{e}}=.26$ ], as was their interaction $\left[F(3,84)=5.13, M S_{\mathrm{e}}=.26\right]$.

Correlations. Simple and partial correlations were determined for the recall groups between pairs of the following variables: actual frequency $(F)$, frequency judgments on the first test $\left(T_{1}\right)$, cued recall $(R)$, and frequency judgments on the second test $\left(T_{2}\right)$. Selected correlation coefficients for Test 1 and Test 2 frequency judgments are set forth in Table 8. The notation is the same as that used previously. For example, $T_{1} F$ is the simple correlation between judgments on the first frequency test and actual frequency, and $T_{2} F / T_{1} R$ is the correlation between judgments on the second frequency test and actual frequency, statistically controlling for the influence of frequency judgments on the first test and recall.

The first four data columns in the upper half of Table 8 correspond to the data columns of Tables 3 and 6. Simple correlations between Test 1 frequency estimates and actual
Table 8

Correlations Involving Frequency Judgments on Tests 1 and 2 by the Recall Groups in Experiment 3

\begin{tabular}{ccccccc}
\hline & \multicolumn{5}{c}{ Test 1 Correlations } \\
\cline { 2 - 7 } Age & $\mathrm{T}_{1} \mathrm{~F}$ & $\mathrm{~T}_{1} \mathrm{~F} / \mathrm{R}$ & $\mathrm{T}_{1} \mathrm{R}$ & $\mathrm{T}_{1} \mathrm{R} / \mathrm{F}$ & $\mathrm{T}_{1} \mathrm{~F} / \mathrm{T}_{2} \mathrm{R}$ & $\mathrm{T}_{1} \mathrm{R} / \mathrm{T}_{2} \mathrm{~F}$ \\
\hline Young & $.59^{*}$ & $.49^{*}$ & $.38^{*}$ & -.07 & $.36^{*}$ & $-.25^{*}$ \\
Elderly & $.50^{*}$ & $.42^{*}$ & $.29^{*}$ & .01 & $.21^{*}$ & $-.21^{*}$
\end{tabular}

\begin{tabular}{|c|c|c|c|c|c|c|}
\hline & \multicolumn{6}{|c|}{ Test 2 Correlations } \\
\hline & $\mathrm{T}_{2} \mathrm{~F}$ & $\mathrm{~T}_{2} \mathrm{~F} / \mathrm{T}_{1} \mathrm{R}$ & $T_{2} R$ & $T_{2} R / T_{1} F$ & $T_{2} T_{1}$ & $\mathrm{~T}_{2} \mathrm{~T}_{1} / \mathrm{FR}$ \\
\hline & $.65^{*}$ & $.12 \dagger$ & $.62^{*}$ & $.37 *$ & $.67^{*}$ & $.51^{*}$ \\
\hline Elderly & $.57^{*}$ & $.17^{*}$ & $.50^{*}$ & $.33^{*}$ & $.73^{*}$ & $.65^{*}$ \\
\hline
\end{tabular}

Note- $T_{1}=$ Frequency-Judgment Test $1, T_{2}=$ Frequency-Judgment Test $2, \mathrm{~F}=$ actual frequency, $\mathrm{R}=$ cued recall. ${ }^{*} p<.01 .+{ }^{*} p<.05$.

frequency and between Test 1 frequency estimates and cued recall were highly reliable for both young and elderly subjects. The related partial correlations, controlling for the influence of cued recall in the former instance and actual frequency in the latter, showed that for both young and elderly subjects, frequency judgments on Test 1 were strongly associated with actual frequency but not with cued recall.

The lower half of Table 8 shows that all simple correlations for Test 2 frequency judgments on the one hand and actual frequency, cued recall, and Test 1 judgments on the other were highly reliable. Partial correlations between frequency estimates on Test 2 and each of the other variables, controlling in each case for the influence of the remaining two variables, revealed a similar pattern for young and elderly subjects: a substantial relation between Test 2 and Test 1 frequency judgments, an intermediatesized one between Test 2 judgments and recall, and a negligible albeit statistically reliable one between Test 2 estimates and actual frequency.

Are the partial correlations for Test 1 and Test 2 frequency judgments different simply because first-order correlations were calculated for Test 1 estimates and second-order correlations for Test 2 estimates? To find out, second-order correlations were determined between Test 1 judgments and actual frequency, removing the influence of Test 2 judgments and recall, and between Test 1 estimates and recall, holding constant the effects of Test 2 estimates and actual frequency. The last two columns in the upper half of Table 8 show the coefficients that were obtained. The only one that was similar to a partial correlation for Test 2 judgments was that involving actual frequency in the case of elderly subjects- -21 for Test 1 judgments and .17 for Test 2 judgments. For the most part, then, Test 1 and Test 2 frequency estimates bore different relations to the variables considered in the correlation analyses.

\section{Discussion}

Three outcomes of Experiment 3 are of interest. One is the markedly poorer frequency estimation on Test 2 following cued recall as compared with distractor activity. Once again, a recall test depressed subsequent frequency judgments. 
Second, partial correlations indicated that Test 1 category-frequency judgments were significantly related to actual frequency but not to the retrieval of category exemplars (availability). Frequency judgments on the second test were associated strongly with estimates given on the first test, moderately with recallability, and only weakly with actual frequency.

The third result of interest is the effect of age. Young and elderly subjects showed similar performance on a number of measures of frequency estimation over frequency levels from 2 to 11 -frequency judgments per se, slopes, and standard deviations. Yet young subjects remembered many more words on the cued recall test than elderly subjects did. If availability, as measured by recallability, were all that were involved in category-frequency estimation, then young subjects should have performed better than elderly subjects on at least some of the frequency measures (but see Kausler, Hakami, \& Wright, 1982, for an age deficit in relative category-frequency judgments). Actually, there was one age difference: Elderly individuals gave larger estimates for categories that were not represented in the list than did young persons. Whether this bias was responsible for the similar performance of young and elderly subjects over the frequency levels from 2 to 11 is debatable; the slopes and standard deviations do not suggest it. In sum, the absence of age effects on frequency estimation combined with their presence in recallability indicates that something more than availability mediates frequency judgments when list instances are overtly categorized at input.

\section{EXPERIMENT 4}

Experiment 4 was similar to the previous study, except that all subjects were given a cued recall test. Some received it before and some after the second set of frequency judgments. This allowed us to answer two questions: First, would the correlations between recall and frequency estimates on Test 2 (and for that matter, on Test 1) be the same under the two conditions? Second, would we observe another dissociation between frequency judgments and availability-specifically, a difference in Test 2 frequency estimates as a function of whether cued recall came before or after the second test-but no difference in recall?

\section{Method}

There were two treatment groups: By comparison with Experiment 3 , the recall-before condition was identical to the recall condition and the recall-after condition was the same as the distractor condition, except that a cued recall test was administered immediately after completion of the second frequency-judgment test. In other respects, the design was the same as that of Experiment 3.

Other than slight editorial changes, the study items were the same as in the previous studies. Overt categorization and feedback dur ing list study were again used. Equipment and other aspects of the procedure were identical to those in Experiments 1 and 2.

Only young persons were tested-17 female and 13 male Mount Allison students. They were selected from the subject pool or were paid volunteers. Each treatment group comprised 15 subjects and about the same number of males and females.

\section{Results}

Frequency judgments. Mean frequency judgments as a function of actual frequency and overall means for each condition are set forth in the first five data columns of Table 9. Recall and test number interacted significantly. Simple effects analyses showed that frequency estimates on Test 2 were significantly lower in the recall-before condition $\left[F(1,28)=6.93, M S_{\mathrm{e}}=7.14\right]$, but that on Test 1 there was no reliable difference between the groups $[F(1,28)<1]$. Other statistically significant effects were due to test number $\left[F(1,28)=41.77, M S_{\mathrm{e}}=1.70\right]$ and frequency $\left[F(3,84)=134.66, M S_{\mathrm{e}}=3.55\right]$, and there was a significant interaction of test number and frequency $\left[F(3,84)=16.22, M S_{\mathrm{e}}=.53\right]$, and of test number, frequency, and recall condition $\left[F(3,84)=6.18, M S_{e}=\right.$ .53]. For the frequency level of 0 , the mean estimate was .15 , a value that did not vary significantly as a function of recall or test condition.

Slopes. Table 9 includes means of the slope index of frequency estimation. Slopes were lower on Test 2 than on Test $1\left[F(1,28)=37.51, M S_{\mathrm{e}}=.55\right]$. Recall condition and test number also interacted, and simple effects tests were therefore performed. Although slopes on Test 2 were lower in the recall-before condition, the difference did not quite reach the .05 level of confidence $[F(1,28)=$ $\left.3.43, M S_{\mathrm{e}}=.06\right]$. Test 1 slopes did not differ significantly $[F(1,28)<1]$.

Standard deviations. The last column of Table 9 describes the mean variability of frequency judgments for each of the four treatment conditions. Variability decreased over tests $\left[F(1,28)=17.19, M S_{\mathrm{e}}=.11\right]$. The significant interaction of test and recall condition dictated an analysis of simple effects. Test 2 variability was substantially less in the recall-before than in the recall-after group $\left[F(1,28)=6.23, M S_{\mathrm{e}}=.44\right]$; Test 1 variability did not differ reliably between groups $[F(1,28)<1]$.

Cued recall. For the frequency levels from 2 to 11 , lenient recall means for the recall-after group were 1.36, $2.54,3.84$, and 4.38 ; for the recall-before group, the means were $1.34,2.31,3.42$, and 4.27 . The difference between the groups was not statistically significant. The increase in recall across actual frequency was highly reliable $\left[F(3,84)=186.30, M S_{\mathrm{e}}=.28\right]$.

Correlations. Correlations involving four variables were determined: actual frequency, frequency judgments on Tests 1 and 2 , and recall scores. Table 10 describes simple and first- and second-order partial correlations for

Table 9

Mean Judged Frequency as a Function of Actual Frequency and Overall Means $(M)$, Slopes, and Standard Deviations (SD) of Judgments in Experiment 4

\begin{tabular}{lcccccccc}
\hline & & \multicolumn{9}{c}{ Actual Frequency } & & & \\
\cline { 2 - 6 } Recall & Test & 2 & 5 & 8 & 11 & $M$ & Slope & $S D$ \\
\hline After & 1 & 2.89 & 5.66 & 8.21 & 9.89 & 6.66 & .78 & 2.03 \\
& 2 & 2.77 & 5.18 & 7.66 & 9.04 & 6.16 & .71 & 1.94 \\
Before & 1 & 2.38 & 5.67 & 7.98 & 10.19 & 6.55 & .86 & 1.96 \\
& 2 & 2.12 & 4.47 & 5.81 & 7.11 & 4.88 & .54 & 1.33 \\
\hline
\end{tabular}


Table 10

Correlations Involving Frequency Judgments on Tests 1 and 2 in Experiment 4

\begin{tabular}{lcccccc}
\hline & \multicolumn{5}{c}{ Test l Correlations } \\
\cline { 2 - 6 } Recall & $\mathrm{T}_{1} \mathrm{~F}$ & $\mathrm{~T}_{1} \mathrm{~F} / \mathrm{R}$ & $\mathrm{T}_{1} \mathrm{R}$ & $\mathrm{T}_{1} \mathrm{R} / \mathrm{F}$ & $\mathrm{T}_{1} \mathrm{~F} / \mathrm{T}_{2} \mathrm{R}$ & $\mathrm{T}_{1} \mathrm{R} / \mathrm{T}_{2} \mathrm{~F}$ \\
\hline After & $.65^{*}$ & $.52^{*}$ & $.46^{*}$ & .01 & $.28^{*}$ & $-.15^{*}$ \\
Before & $.67^{*}$ & $.54^{*}$ & $.46^{*}$ & .02 & $.31^{*}$ & -.09
\end{tabular}

Test 2 Correlations

\begin{tabular}{ccccccc} 
& $T_{2} F$ & $T_{2} F / T, R$ & $T_{2} R$ & $T_{2} R / T_{1} F$ & $T_{2} T_{1}$ & $T_{1} T_{1} / F R$ \\
\hline After & $.66^{*}$ & $.11 \dagger$ & $.54 *$ & $.22^{*}$ & $.84^{*}$ & $.72 *$
\end{tabular}

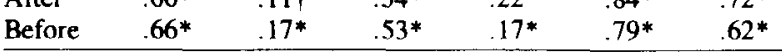

Note- $T_{1}=$ Frequency-Judgment Test $1, T_{2}=$ Frequency-Judgment

Test $2, \mathrm{~F}=$ actual frequency, $\mathrm{R}=$ cued recall. ${ }^{*} p<.01 . \quad+p<.05$.

selected pairs of these variables. The presentation is the same as that in Experiment 3 (see Table 8 for comparison).

The first four data columns in the upper half of Table 10 contain simple and first-order correlations for Test 1 frequency estimates. All simple correlations were statistically significant. First-order correlations in the recall-after and recall-before groups were virtually identical and were in agreement with the pattern observed in the previous study: Judgments on the first test were reliably associated with actual frequency but not with cued recall.

The bottom half of Table 10 reveals that all simple correlations for Test 2 judgments were substantial and statistically significant. The second-order correlations indicated that Test 2 frequency judgments in both groups, as in Experiment 3 , were most strongly associated with estimates made on Test 1 and considerably less so with actual frequency. The relation of Test 2 estimates to cued recall, though statistically significant, was not as marked as in the previous study, although it was never less than the association between Test 2 estimates and actual frequency.

To determine whether differences in the pattern of coefficients for Tests 1 and 2 were attributable to comparing first- and second-order partial correlations, second-order coefficients were calculated for Test 1 frequency estimates and are shown in the two rightmost columns in the top half of Table 10. The differences between comparable Test 1 and Test 2 correlations were not eliminated.

\section{Discussion}

Experiment 4 has two important implications: First, the correlations between Test 2 frequency estimates and recall (availability) found in Experiment 3 are not entirely attributable to the administration of a recall test before Test 2. Reliable positive correlations were obtained regardless of whether cued recall preceded or followed Test 2. Still, the correlations in support of availability as a basis for Test 2 frequency judgments were not very impressive; and as a basis for Test 1 judgments, they were nonexistent.

Second, Experiment 4 produced another dissociation of frequency judgments and recall. Specifically, Test 2 frequency estimates of the recall-after and recall-before groups diverged significantly, but recall did not. Together with the correlation results, this suggests that something in addition to availability played a role in Test 2 frequency judgments.

\section{EXPERIMENT 5}

Our reservations about the use of an availability heuristic following explicit categorization and feedback during list presentation have stemmed partly from the rather low correlations observed between judged frequency and cued recall, statistically controlling for the influence of actual frequency. But how strong can such associations be? What baseline should be applied in evaluating them? Experiment 5 was an attempt to find out.

\section{Method}

The materials and equipment were the same as in Experiments 1,2 , and 4 . One procedural change was that subjects were given practice at the outset of an experiment session in responding at the computer keyboard in the paced fashion to be used in later testing (nothing was said about the kind of test to be given later, however). A sequence of five words from outside the materials pool was presented on the monitor. For each item, individuals waited $10 \mathrm{sec}$, said aloud a number from 0 to 99 (it had to be different from the one given previously), and then pressed the space key. The end of the $10 \mathrm{sec}$ was marked by a coincident .5 -sec beep and a printed prompt on the monitor: "Please say a number and press the space bar." After this exercise came learning of the category names, and list study in the manner of the overt categorization procedure of the previous experiments

At the end of the list, subjects received a retrieval or a frequencyjudgment test. Both entailed responding to 30 category names in the 10 -sec paced fashion of the practice exercise. Individuals given the retrieval judgment test (the retrieval group) were asked to use the $10 \mathrm{sec}$ for each category "to remember as many words as you can belonging to that category that were in the long word list." As each instance was silently remembered, subjects were to put a tally mark at the appropriate place on a test sheet having spaces on it corresponding to the 30 categories. It was emphasized that a tally mark was to be made only when an instance was actually remembered. Individuals worked at the retrieval task until the beep signaling the end of the response interval, at which point they said aloud the number of tally marks they had made. Subjects given the frequency-estimation task (the frequency group) simply waited $10 \mathrm{sec}$ after each category appeared and then said a number and pressed the space bar. They were told to use the time "to think about your estimate before you make it." A 12.5 -min cued recall test concluded the testing in both conditions.

The subjects were 30 students, 15 males and 15 females, from the Mount Allison subject pool. Fifteen persons consisting of about equal numbers of males and fermales were assigned to each test condition.

\section{Results}

Estimates made by the retrieval group are hereafter called retrieval judgments; estimates made by the frequency group, frequency judgments.

Retrieval and frequency judgments. The first five data columns of Table 11 contain mean estimates at each of the four frequency levels from 2 to 11 , as well as overall means for each judgment condition. Estimates in both groups increased significantly with actual frequency $\left[F(3,84)=79.73, M S_{e}=2.02\right]$. Frequency estimates were also substantially higher than retrieval estimates 
Table 11

Mean Retrieval and Frequency Judgments as a Function of Actual Frequency and Overall Means $(M)$, Slopes, and Standard Deviations (SD) of Judgments in Experiment 5

\begin{tabular}{lccccccc}
\hline & \multicolumn{3}{c}{ Actual Frequency } & & & \\
\cline { 2 - 6 } Judgment & 2 & 5 & 8 & 11 & $M$ & Slope & $S D$ \\
\hline Retrieval & 1.74 & 3.08 & 4.03 & 4.97 & 3.46 & .35 & .81 \\
Frequency & 2.69 & 5.46 & 8.10 & 10.19 & 6.61 & .84 & 2.14 \\
\hline
\end{tabular}

$\left[F(1,28)=24.80, M S_{\mathrm{e}}=12.02\right]$, and the difference widened as actual frequency increased $[F(3,84)=13.15$, $\left.M S_{\mathrm{e}}=2.02\right]$. The frequency group also made significantly larger estimates for zero-frequency categories than did the retrieval group, .31 versus $.01[F(1,28)=6.63$, $\left.M S_{\mathrm{e}}=.10\right]$.

Slopes and standard deviations. The mean slopes reported in Table 11 indicate that frequency subjects discriminated among actual frequencies significantly better than did retrieval subjects $\left[F(1,28)=16.52, M S_{e}=.11\right]$. Mean standard deviations are also shown in Table 5. Frequency judgments were much more variable than retrieval estimates $\left[F(1,28)=20.39, M S_{\mathrm{e}}=.65\right]$.

Cued recall. Means for leniently scored recall as a function of the four frequency levels from 2 to 11 were 1.53 , $2.76,3.86$, and 4.78 for the retrieval condition and 1.36, $2.59,3.27$, and 4.04 for the frequency condition. Actual frequency had a reliable effect $\left[F(3,84)=182.44, M S_{\mathrm{e}}=\right.$ .27], but the better recall of the retrieval subjects only approached statistical significance $\left[F(1,28)=3.66, M S_{\mathrm{e}}=\right.$ $1.43, p<.07]$, as did the interaction of actual frequency and test condition $\left[F(3,84)=2.36, M S_{\mathrm{e}}=.27, p<.08\right]$.

Correlations. The correlation analysis and terminology were the same as those applied to the data of Experiments 1 and 2 , the only difference being that for the retrieval group, the judgments were retrieval judgments. Table 12 shows that retrieval and frequency judgments were both significantly related to actual frequency, even when the influence of cued recall was statistically controlled. The zero-order associations of both judged retrieval and judged frequency to cued recall were also substantial. But while the association remained strong in the retrieval group when the effect of actual frequency was removed, it vanished in the frequency group.

\section{Discussion}

Experiment 5 replicated the previously found pattern of correlations when frequency judgments were made shortly after list presentation and categorization and feed-

\section{Table 12}

Correlations Involving Retrieval and

Frequency Judgments in Experiment 5

\begin{tabular}{lcccc}
\hline & \multicolumn{4}{c}{ Correlation } \\
\cline { 2 - 5 } Judgment & $\mathrm{TF}$ & $\mathrm{TF} / \mathrm{R}$ & $\mathrm{TR}$ & $\mathrm{TR} / \mathrm{F}$ \\
\hline Retrieval & $.74^{*}$ & $.35^{*}$ & $.83^{*}$ & $.63^{*}$ \\
Frequency & $.60^{*}$ & $.47^{*}$ & $.43^{*}$ & .06 \\
\hline
\end{tabular}

Note-T $=$ judgment (retrieval or frequency) test, $F=$ actual frequency, $\mathbf{R}=$ cued recall. $*_{p}<.01$. back occurred during list presentation. That is, there was a strong relation between judged and actual frequency independent of cued recall, but only a negligible relation between judged frequency and cued recall independent of actual frequency. The retrieval group, by contrast, gives an idea of what the relation between frequency estimation and recall can be if estimates are strongly tied to the recollection of instances. The correlation of .63 indicates that roughly $40 \%$ of the variance in retrieval judgments was accounted for. It seems evident that the underlying retrieval process must be quite different from the preferred strategy for estimating frequency shortly after the end of a list that has been subjected to strong categorical encoding of its members. For in addition to the higher partial correlation between judgments and recall, the retrieval group also gave estimates that were lower, less discriminating, and less variable than those in the frequency group.

The findings from the retrieval condition may be compared with those of the no-categorization conditions of Experiment 1, which did not involve instance categorization and feedback during list presentation. In that experiment, frequency estimates preceded by a recall test were similar to retrieval judgments in the current study, as was the partial correlation between frequency estimates and recall, .66. There was much less similarity when the recall test came after frequency estimates. For example, the partial correlation between frequency judgments and recall was only .30 . These comparisons suggest that when list members are not categorized during presentation, frequency estimates are strongly based on the retrieval of instances if they have been preceded by a cued recall test and moderately based on such retrieval when they have not.

\section{GENERAL DISCUSSION}

In the research reported in this article, we sought two kinds of evidence for availability as a strategy for making frequency estimates: (1) positive correlations between frequency estimates and cued recall (a measure of availability); and (2) parallel movement in frequency estimation and recall in response to changes in independent variables.

First, with respect to the correlational evidence, moderate to strong positive correlations between frequency estimates and recall (holding constant the influence of actual frequency) were obtained in the presence of any one or more of the following conditions: list instances not explicitly categorically encoded during study; a cued recall test administered prior to making frequency estimates; and testing delayed by approximately a week. Each of these conditions appears to foster judging frequency on the basis of retrieved instances.

A serious limit on the generality of availability occurs when individuals are required to categorize list members aloud during study and are given feedback about their categorizations. Short-term frequency tests in the absence of prior cued recall consistently produced low to negligible correlations between frequency judgments and recall. 
In these circumstances, overt categorization of list members during study evidently obviates the necessity for their later retrieval as a basis for estimating frequency.

As for parallel movement in frequency estimates and recall, this was the exception rather than the rule in the present experiments. Thus, frequency judgments were impaired when preceded by cued recall (Experiments 1,2, and 4); but variation in the position of the recall test relative to frequency estimation left recall performance unaffected or moved it in a direction opposite that of frequency estimates. Age also had a different influence on the two dependent measures: Frequency judgments were largely independent of age, but young subjects recalled many more words than did elderly subjects. Such dissociations occurred largely within the context of overt categorization of list members during study and are therefore not surprising. They go hand in hand with the presence of low correlations between frequency judgments and recall and indicate a limited role for availability in the presence of strong categorical encoding of list items at the time of study.

But the dissociations contain a much more important message: Parallel effects on frequency judgments and recall due to manipulations in independent variables cannot be taken as conclusive support for availability (see, e.g., Greene, 1989; Lewandowsky \& Smith, 1983; Williams \& Durso, 1986). Experiment 1 in particular shows that such a finding is uninformative. Categorization during list presentation led to improved frequency judgments and better recall. The correlations indicated, however, that availability was actually more in evidence when list items were not categorized during study. Experiment 2 makes a similar point. Frequency judgments and recall were both higher when testing occurred immediately after list study as compared with 1 week later. Yet partial correlations showed that reliance on availability was, if anything, greater after 1 week. The pervasive influence of cued recall in advance of frequency estimates in these studies suggests, in a different way, the same sort of thing. Recall lowered frequency judgments on a subsequent test, but the correlations indicated a stronger role for availability in such judgments. In short, conditions favoring recall may also favor frequency estimation, but that does not mean that availability is at work. And even in situations in which it is, it does not follow that frequency judgments will be improved.

Given the lack of evidence for availability when the study procedure consists of overt categorization and feedback, what other theoretical accounts might apply? One possibility is that category instances are stored separately during list study (each with a strong episodic link to the category name) and that judgments of their occurrence frequency are based on the strength of a composite of instance memories. This is the stance of Hintzman's (1988) MINERVA 2 model: Each presentation of an item creates a separate trace, but absolute frequency judgments are determined by familiarity-the strength of a composite echo of memory traces in response to the presentation of a probe, here, the category name.

Another hypothesis is that the category label occurs as an implicit associative response (Underwood, 1965) to each study-list presentation of a category exemplar. Frequency judgments are made on the basis of frequency information that accrues as an attribute of the stored category name (see, e.g., Alba et al., 1980; Freund \& Hasher, 1989; Hasher \& Zacks, 1984). This interpretation has considerable appeal, given the present data showing that frequency judgments were more discriminating when list items were categorized aloud.

In conclusion, the way in which people solve categoryfrequency estimation problems will depend on the relevant information that is stored in memory and on the retrieval conditions that apply at the time of frequency testing. Any of a number of underlying processes could operate (cf. Begg, Maxwell, Mitterer, \& Harris, 1986; Jonides \& Naveh-Benjamin, 1987). The present investigations identify both encoding and retrieval circumstances that influence adoption of an availability strategy. On the encoding side, instance retrieval as a basis for frequency estimates is more likely in the absence of explicit categorization of items during list study and less likely if such categorization has occurred. As for retrieval conditions, reliance on availability is encouraged by a recall test prior to frequency judgments and by a long retention interval. The experiments also demonstrate that when a treatment improves both frequency estimates and the recallability of instances, it is no guarantee that an availability heuristic is operating.

\section{REFERENCES}

Alba, J. W., Chromiak, W., Hasher, L. , Attig, M. (1980). Automatic encoding of category size information. Joumal of Experimental Psychology: Human Learning \& Memory, 6, 370-378.

BARsalou, L. W., \& Ross, B. H. (1986). The roles of automatic and strategic processing in sensitivity to superordinate and property frequency. Journal of Experimental Psychology: Learning, Memory, \& Cognition, 12, 116-134.

Battig, W. F., Montague, W. E. (1969). Category norms of verbal items in 56 categories: A replication and extension of the Connecticut category norms. Journal of Experimental Psychology Monographs, $\mathbf{8 0}$ (3, Pt. 2).

BegG, I., Maxwell, D. Mitterer, J. O. , Harris, G. (1986). Estimates of frequency: Attribute or attribution? Journal of Experimental Psychology: Learning, Memory, \& Cognition, 12, 496-508.

Birnbaum, I. M., Taylor, T. H., Johnson, M. K., Raye, C. L. (1987). Is event frequency encoded automatically? The case of alcohol intoxication. Joumal of Experimental Psychology: Leaming, Memory, \& Cognition, 13, 251-258.

Bruce, D., \& READ, J. D. (1988). The how and why of memory for frequency. In M. M. Gruneberg, P. E. Morris, \& R. N. Sykes (Eds.), Practical aspects of memory: Current research and issues (Vol. 1 , pp. 317-322). Chichester, U.K.: Wiley

Ekstrom, R. B., French, J. W., Harman, H. H., a Dermen, D. (1976). Kit of factor referenced cognitive tests. Princeton, NJ: Educational Testing Service.

Freund, J. S., \& HaSher, L. (1989). Judgments of category size: Now you have them, now you don't. American Joumal of Psychology, 102, 333-352. 
Greene, R. L. (1984). Incidental learning of event frequency. Memory \& Cognition, 12, 90-95.

GREENE, R. L. (1986). The effects of intentionality and strategy on memory for frequency. Journal of Experimental Psychology: Learning, Memory, \& Cognition, 12, 489-495.

GREENE, R. L. (1988). Generation effects in frequency judgment. Journal of Experimental Psychology: Learning, Memory, \& Cognition, 14, 298-304.

GREENE, R. L. (1989). On the relationship between categorical frequency estimation and cued recall. Memory \& Cognition, 17, 235-239.

HASHER, L., ZACKs, R. T. (1984). Automatic processing of fundamental information: The case of frequency of occurrence. American Psychologist, 39, 1372-1388.

HiNTZMAN, D. L. (1988). Judgments of frequency and recognition memory in a multiple-trace memory model. Psychological Review, 95 , 528-551.

HuLtsCh, D. (1975). Adult age differences in retrieval: Trace-dependent and cue-dependent forgetting. Developmental Psychology, 11, 197-201.

JoNides, J., NAVEH-BENJAMIN, M. (1987). Estimating frequency of occurrence. Journal of Experimental Psychology: Learning, Memory, \& Cognition, 13, 230-240.

Kausler, D. H., Hakami, M. K., \& Wright, R. E. (1982). Adult age differences in frequency judgments of categorical representations. Journal of Gerontology, 37, 365-371.

Lewandowsky, S., Smith, P. W. (1983). The effect of increasing the memorability of category instances on estimates of category size. Memory \& Cognition, 11, 347-350.

McEvoy, C. L., \& NeLSON, D. L. (1982). Category name and instance norms for 106 categories of various sizes. American Journal of Psychology, 95, 581-634.

Naveh-Benjamin, M., Jonides, J. (1986). On the automaticity of frequency coding: Effects of competing task load, encoding strategy, and intention. Journal of Experimental Psychology: Learning, Memory, \& Cognition, 12, 378-386.

TVERSKY, A., KAHNEMAN, D. (1973). Availability: A heuristic for judging frequency and probability. Cognitive Psychology, 5, 207-232.

UNDERWOOD, B. J. (1965). False rocognition produced by implicit verbal responses. Joumal of Experimental Psychology, 70, 122-129.

Williams, K. W., Durso, F. T. (1986). Judging category frequency: Automaticity or availability? Journal of Experimental Psychology: Learning, Memory, \& Cognition, 12, 387-396.

(Manuscript received November 28, 1988; revision accepted for publication December 12, 1990.) 